\title{
Male Breast Glandular Liposculpture Challenges
}

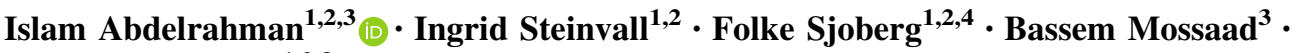 \\ Moustafa Elmasry $1,2,3$
}

Received: 30 April 2018/Accepted: 2 May 2018/Published online: 8 May 2018

(C) Springer Science+Business Media, LLC, part of Springer Nature and International Society of Aesthetic Plastic Surgery 2018

Level of Evidence $V$ This journal requires that authors assign a level of evidence to each article. For a full description of these Evidence-Based Medicine ratings, please refer to the Table of Contents or the online Instructions to Authors www.springer.com/00266.

\section{Dear Sir,}

We appreciate the positive comments on our paper [1] raised by Dr Shirol in his letter to the Editor, and we acknowledge that he agrees with us on the importance and relevance of the study. It is important to do accurate follow-up in the field of innovative plastic surgery [2], and we think that it is a successful strategy to combine clinical follow-up with research.

We agree that keeping the incisions away from the breast aesthetic unit and NAC would result in a better appearance of the front chest wall and will reduce the incidence NAC retraction, hypopigmentation, or shape distortion due to scarring.

In our publication, $92 \%$ of the patients who had the surgery using combined liposuction and liposculpture technique were highly satisfied with the results, which confirms the efficacy of the technique. It is worth

Islam Abdelrahman

islam.abdelrahman@liu.se; islammohamedy@yahoo.com

1 The Department of Hand Surgery, Plastic Surgery and Burns, Linköping University, Linköping, Sweden

2 Department of Clinical and Experimental Medicine, Linköping University, Linköping, Sweden

3 The Plastic Surgery Unit, Surgery Department, Suez Canal University, Ismailia, Egypt

4 Department of Anaesthesiology and Intensive Care, Linköping University, Linköping, Sweden mentioning that no patients developed a hematoma during the whole study; additionally, a minority of patients had complained of diminished sensation in the NAC, which was eventually improving during the 6-month period following the operation. Thus, we would like to clarify that the used cannulas (Mercedes and Fat Disruptor) did not result in any hematomas nor higher rates of diminished NAC sensation.

We also agree that postoperative pressure garments should be used to prevent later complications. However, we think that applying the garment for continuous 10 days could carry a possible risk of missing early hematoma diagnosis and evacuation. Furthermore, it is hard to convince patients who reside in relatively hot weather (Egypt) not to take a shower for 10 days.

Finally, we acknowledge the authors' ability to use the tumescent anesthesia; unfortunately, it was not successful in our hands, as the patients were irritated and most of them were converted to general anesthesia during the procedure.

\section{Compliance with Ethical Standards}

Conflict of interest The authors declare that they have no conflicts of interest to disclose.

\section{References}

1. Abdelrahman I, Steinvall I, Mossaad B, Sjoberg F, Elmasry M (2018) Evaluation of glandular liposculpture as a single treatment for grades I and II gynaecomastia. Aesthet Plast Surg 16:1-9

2. Ridha H, Colville RJ, Vesely MJ (2009) How happy are patients with their gynaecomastia reduction surgery? J Plast Reconstr Aesthet Surg 62:1473-1478 